\title{
Polar thermosphere-stratosphere photochemical coupling experiment: Two rocket measurements in polar winter at $69^{\circ} \mathrm{N}$
}

\author{
Naomoto Iwagami ${ }^{1}$, Hiromasa Yamamoto ${ }^{2}$, Ken-ichi Yajima ${ }^{2}$, Hiroyuki Sekiguchi ${ }^{2}$, Takashi Watanabe ${ }^{3}$, Katsuhisa Suzuki $^{4}$, \\ Kazuo Shibasaki ${ }^{5}$, Hiroshi Amemiya ${ }^{6}$, Masayuki Yamamoto ${ }^{7}$, and Takayuki Ono ${ }^{7}$ \\ ${ }^{1}$ Department of Earth and Planetary Physics, University of Tokyo, Bunkyo, Tokyo 113, Japan \\ ${ }^{2}$ Department of Physics, Rikkyo University, Toshima, Tokyo 171, Japan \\ ${ }^{3}$ Tsukuba College of Technology, Tsukuba, Ibaraki 305, Japan \\ ${ }^{4}$ Faculty of Education, Yokohama National University, Hodogaya, Yokohama 240, Japan \\ ${ }^{5}$ Faculty of Literature, Kokugakuin University, Shibuya, Tokyo 150, Japan \\ ${ }^{6}$ Institute of Physical and Chemical Research, Wako, Saitama 351, Japan \\ ${ }^{7}$ Faculty of Science, Tohoku University, Aoba, Sendai 980, Japan
}

(Received December 12, 1997; Revised May 11, 1998; Accepted May 20, 1998)

Two rocket experiments were carried out just before and after the polar night at Andoya $\left(69^{\circ} \mathrm{N}\right)$, Norway to investigate transport of nitric oxide produced by auroral processes into the middle atmosphere and its influence on the ozone chemistry. Nitric oxide densities of $(2-5) \times 10^{8} \mathrm{~cm}^{-3}$ found in the $70-90 \mathrm{~km}$ region are one to two orders of magnitude larger than those at middle latitudes. The measured density profiles appear to agree semiquantitatively with model simulations which includes auroral processes. The influence on ozone densities in the $70-90 \mathrm{~km}$ region due to such enhanced nitric oxide abundance is found to be still insignificant as compared to that due to transport in the middle of February, one month after the end of polar night and one month before the spring equinox. The larger ozone densities found in February (in spite of longer sunlit duration) than in November in the 40-60 km region again support predominance of transport over photochemical destruction.

\section{Introduction}

A possibility that NO (nitric oxide) produced in the lower thermosphere by auroral particle precipitation may be transported downward to perturb the $\mathrm{O}_{3}$ (ozone) chemistry in the stratosphere has been pointed out in the 1980s by several model simulations (e.g. Solomon et al., 1982; Brasseur, 1984). Since the production rate of NO in the lower thermosphere is much larger than that in the stratosphere even without auroral perturbation, there is a considerable possibility for such coupling to occur. According to those theoretical simulations the downward transport of NO does not occur at mid-latitudes or during summer even at high latitudes because of fast photodissociation. The time constant for photodissociation of NO in the thermosphere of about 2 days (Minschwaner and Siskind, 1993) is shorter than that for transport due to vertical eddy diffusion of several days as discussed in a latter section. During polar winter NO produced in the lower thermosphere by auroral particle precipitation is expected to pass through the mesosphere and to reach the stratosphere because of slow photodissociation due to short sunlit duration. The downward advection expected from the summer to winter circulation in the middle atmosphere may contribute to increase the downward transport. Once NO reaches the mid to lower mesosphere, its lifetime becomes longer because of less photodissociation due to absorption in the $\mathrm{O}_{2}$ Schumann-

Copy right $(C)$ The Society of Geomagnetism and Earth, Planetary and Space Science (SGEPSS); The Seismological Society of Japan; The Volcanological Society of Japan; The Geodetic Society of Japan; The Japanese Society for Planetary Sciences.
Runge band and self-absorption in the $\delta$ band (Minschwaner and Siskind, 1993); $\mathrm{NO}_{x}$ (nitrogen oxides $=\mathrm{NO}+\mathrm{NO}_{2}$ ) has a lifetime as long as a year in the stratosphere (Solomon $e t$ al., 1982).

Solomon and Garcia (1984) pointed out the influence of such auroral $\mathrm{NO}$ in the retrieval of $\mathrm{O}_{3}$ densities by the Nimbus 7 SBUV (Solar Backscatterd Ultraviolet) experiment. Rusch and Clancy (1989) also discussed that influence of NO transport was found in the $\mathrm{O}_{3}$ data of SBUV and SME (Solar Mesosphere Explorer) until one month after the spring equinox. Russell et al. (1984) discussed that the large mixing ratio of $\mathrm{NO}_{2}$ found in the polar stratosphere by LIMS (Limb Infrared Monitor of the Stratosphere) of the Nimbus 7 was due to the transport of NO from the thermosphere.

It has already been established that the NO abundance in the lower thermosphere is larger at high latitudes than at lower latitudes. Several satellite measurements such as the Atmosphere Explorer C and D (e.g. Rusch and Barth, 1975) found 3 to 10 times larger NO abundance with high variability in the lower thermosphere at high latitudes than at lower latitudes. However, there is only limited experimental evidence for downward transport of NO during polar winter. This is because those satellite measurements did not detect NO densities below $100 \mathrm{~km}$, and just a few rocket measurements in the mesosphere have been performed at high latitudes. Iwagami and Ogawa (1980) used a rocket-born $\gamma$ band gas-correlation radiometer in austral winter at Syowa $\left(69^{\circ} \mathrm{S}\right)$, and found NO densities of about $1 \times 10^{8} \mathrm{~cm}^{-3}$ in the $70-110 \mathrm{~km}$ region. Horvath and Frederick (1985) using a rocket-born chemiluminescence sensor at Poker Flat $\left(65^{\circ} \mathrm{N}\right)$ 
found NO mixing ratios more than $100 \mathrm{ppbv}$ at $52 \mathrm{~km}(1.7$ $\times 10^{9} \mathrm{~cm}^{-3}$ ) and their steep positive gradient above $50 \mathrm{~km}$ in winter.

Recently Siskind and Russell (1996) and Siskind et al. (1997) investigated the NO distribution up to $120 \mathrm{~km}$ based on the data of the HALOE (Halogen Occultation Experiment) on board the UARS (Upper Atmosphere Research Satellite), and clearly showed transport of auroral NO into the midlatitude stratosphere by utilizing the correlation between $\mathrm{NO}$ and $\mathrm{CH}_{4}$ mixing ratios. They suggested that latitudinal mixing by planetary wave breaking played an important role in transporting auroral NO to the lower latitudes. They also found an absence of excess NO in the polar mesosphere after the spring equinox in contradiction to theoretical predictions (e.g. Brasseur, 1993). However, the HALOE data in the winter hemisphere are limited at lower latitudes than $55^{\circ}$ because of its occultation geometry, and cannot reveal the situation under the polar night conditions.

The purpose of the present experiments is to confirm experimentally the down-ward transport of NO during polar winter where information is still rare, and to examine the coupling with the stratospheric $\mathrm{O}_{3}$ chemistry by measuring $\mathrm{NO}$ and $\mathrm{O}_{3}$ simultaneously. Since auroral activity as well as solar activity may perturb the middle atmosphere through this interesting photochemical coupling mechanism, experimental investigation of this process has a significant importance for our comprehensive understanding of the middle atmosphere and the solar-terrestrial environment.

\section{Instrumentation}

The following three remote and two in-situ sensors were flown on board each of the two sounding rockets S310.22 and S310.23:

1.UV gas-correlation filter radiometer to measure $\mathrm{NO}$ densities at $60-200 \mathrm{~km}$;

2. Near IR filter radiometer to measure $\mathrm{O}_{3}$ densities at 60 $100 \mathrm{~km}$;

3. UV filter radiometer to measure $\mathrm{O}_{3}$ densities at 30-70 $\mathrm{km}$;

4. Impedance probe to measure electron densities at 80 $200 \mathrm{~km}$;

5. Faraday cup to measure negative/positive ion densities at $60-200 \mathrm{~km}$.

The UV gas-correlation radiometer measured the $\chi(1,0) 215$ $\mathrm{nm}$ band fluorescence of NO with a spectral band width of $12 \mathrm{~nm}$. A pair of cells (NO gas filled and empty) were used to discriminate the $\chi(1,0) 215 \mathrm{~nm}$ band emission from the background emissions such as the Rayleigh scattered sunlight and the star light (Iwagami, 1981; Iwagami and Ogawa, 1981).

The near IR radiometer measured the $\mathrm{O}_{2}$ infrared atmospheric $(0,0) 1.27 \mu \mathrm{m}$ band airglow with cooled Ge (S310.22) or InGaAs (S310.23) detectors at the band center and at the wing with spectral band widths of $6 \mathrm{~nm}$. Under sunlit conditions the volume emission rate of this $\mathrm{O}_{2}$ airglow is in proportion to $\mathrm{O}_{3}$ density although corrections for the selfabsorption and quenching are needed below $70 \mathrm{~km}$ (Yamamoto et al., 1997).

The UV radiometer for stratospheric $\mathrm{O}_{3}$ measured the solar irradiance with 4 pairs of radiometers; each is a pair of a UV wavelength (265 nm, $290 \mathrm{~nm}, 300 \mathrm{~nm}$ or $307 \mathrm{~nm})$ and a visible wavelength of $420 \mathrm{~nm}$ with spectral band widths of 10-14 nm. The reference signal measured at $420 \mathrm{~nm}$ was used to compensate for the modulation in the output signal due to attitude change of the rocket (Ogawa and Watanabe, 1994).

The impedance probe with a $1.2 \mathrm{~m}$ ribbon antenna developed perpendicular to the rocket spinning axis measured the upper hybrid resonance frequency of ambient plasma, and determined electron densities in the range of $10^{3}-10^{6}$ $\mathrm{cm}^{-3}$ with an accuracy of $3 \%$ every 0.3 second (Oya and Obayashi, 1967).

The Faraday cup was developed $30 \mathrm{~cm}$ apart from the rocket skin facing to the direction perpendicular to the spinning axis of the rocket. It measured negative/positive ion currents by applying positive/negative biases on the probe alternately (Amemiya and Nakamura, 1996).

\section{Experiments and Geophysical Conditions}

The sounding rockets $S 310.22$ and S310.23 were launched at Andoya Rocket Range $\left(69^{\circ} \mathrm{N}, 16^{\circ} \mathrm{E}\right)$ at $0752 \mathrm{UT}$ on 16 February 1994 and 1020 UT on 24 November 1994, respectively. Both instances were just after the local sunrise when the solar zenith angles were $88.6^{\circ}$ and $89.9^{\circ}$, respectively, at the range (see Fig. 1). The sunlit durations on the days of the experiments on the ground were 7 hours and 1 hour, respectively. At the latitude of the range the polar night started in the beginning of December, and ended in the middle of January. The February experiment was carried out one month after the end of the polar night, and the November experiment just before the beginning of the polar night. Both sounding rockets were launched in the northwest direction, and reached the apogees of about $200 \mathrm{~km}$ at about 220 seconds after the launch. All of the five kinds of instruments worked well, and excellent data sets were obtained although

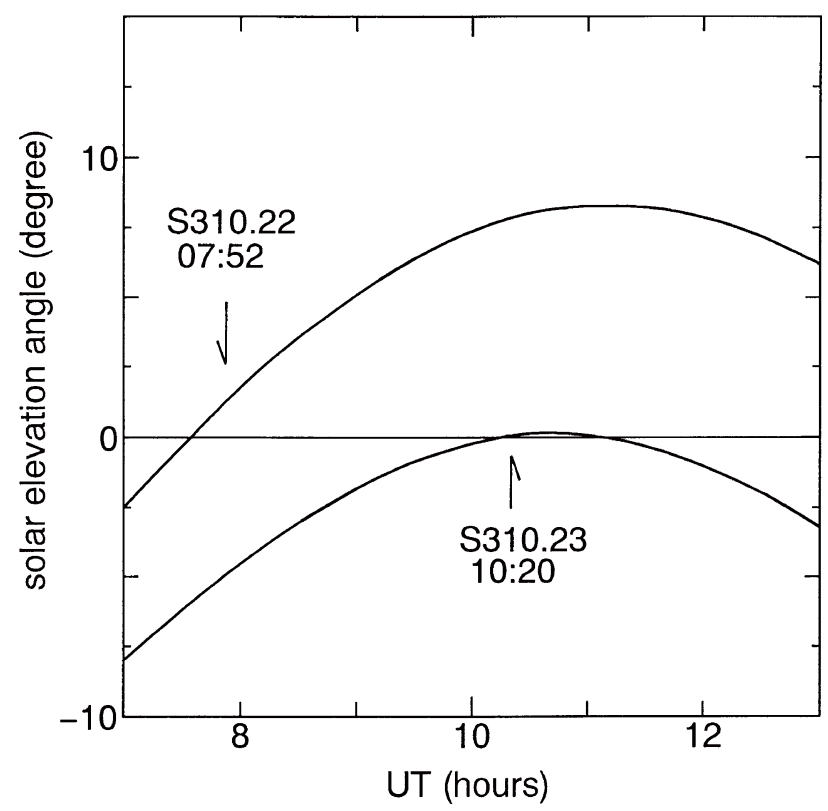

Fig. 1. Solar elevation angles on the days of the S310.22 (16 February 1994) and S310.23 (24 November 1994) experiments at Andoya Rocket Range $\left(69^{\circ} \mathrm{N}, 16^{\circ} \mathrm{E}\right)$. 
some telemetry noise contaminated the data.

The geomagnetic and auroral conditions for a few days prior to the experiments are shown in Figs. 2(a) and 2(b) where the deviation of the geomagnetic horizontal component $\Delta H$ and the riometer (relative ionospheric opacity meter) absorption measured at the range are plotted. It is found in the figure that the $S 310.22$ experiment on 16 February was carried out during a very active period whereas the $S 310.23$ experiment on 24 November during a rather quiet period. Even at the launch of the S310.22 experiment at the local

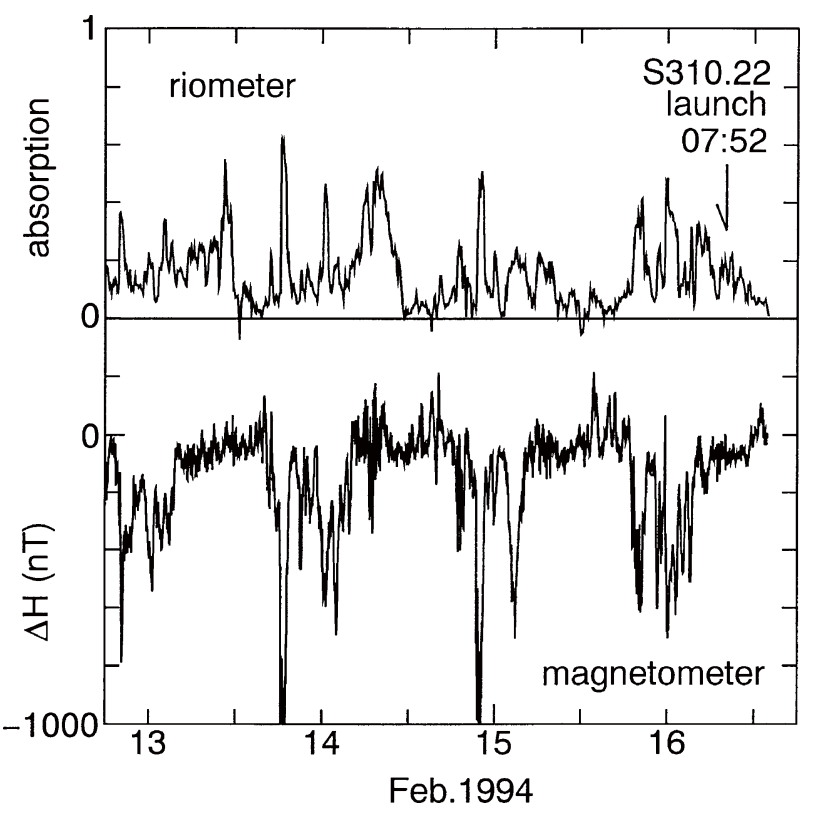

Fig. 2(a). Deviation of geomagnetic horizontal component $\Delta H$ and 32.3 $\mathrm{MHz}$ riometer absorption measured at the range for a few days prior to the launch of the S310.22 experiment on 16 February 1994.

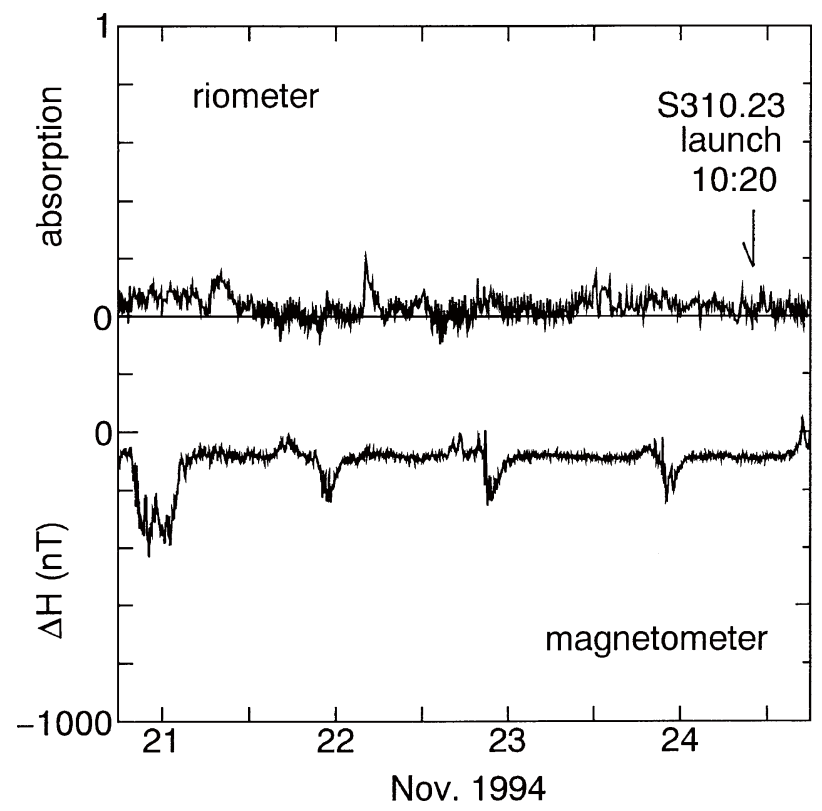

Fig. 2(b). Same as Fig. 2(a) but of the S310.23 experiment on 24 November 1994. sunrise considerable auroral particle precipitation was expected because absorption of about $15 \%$ is seen in the riometer data. Although no definite absorption was seen at the launch of the S310.23 experiment, signatures of auroral particle precipitation are seen in the measured electron density profiles of both experiments as will be discussed later.

Prior to the $\mathrm{S} 310.22$ experiment significant auroral storms occurred around every midnight. The $K p$ index at the launch was 3 , and the average for 13-15 February was 4+. On the other hand, small auroral storms also occurred every midnight prior to the $\mathrm{S} 310.23$ experiment. The $K p$ index at the launch was 1-, and the average for 21-23 November was 1+. By using the statistical relation given by Foster et al. (1986), the energy influxes due to auroral particle precipitation may be estimated from those 3-day mean $K p$ indexes. They are 9 erg $\mathrm{cm}^{-2} \mathrm{~s}^{-1}$ and $0.3 \mathrm{erg} \mathrm{cm}^{-2} \mathrm{~s}^{-1}$ for the S310.22 and S310.23 experiments, respectively, where uniform precipitation over the polar cap of $3000 \mathrm{~km}$ in diameter is assumed. The former energy influx produces visible aurora displays whereas the latter sub-visible ones. The solar activity changed as $F_{10.7}$ (index of solar radio flux at $10.7 \mathrm{~cm}$ ) $=102$ at the $\mathrm{S} 310.22$ experiment in February to $F_{10.7}=77$ at the S310.23 experiment in November.

\section{Results and Discussions}

\subsection{Nitric oxide}

In Fig. 3 the NO density profiles measured during both ascent and descent are plotted. The error bars represent the uncertainty due to numerical differentiation of the data with random noise. Systematic errors will be discussed later in this section. The NO density profiles measured by the S310.22 ascent and descent show peaks of $4 \times 10^{8} \mathrm{~cm}^{-3}$ at $105 \mathrm{~km}$, and those by the $\mathrm{S} 310.23$ show no clear peak but

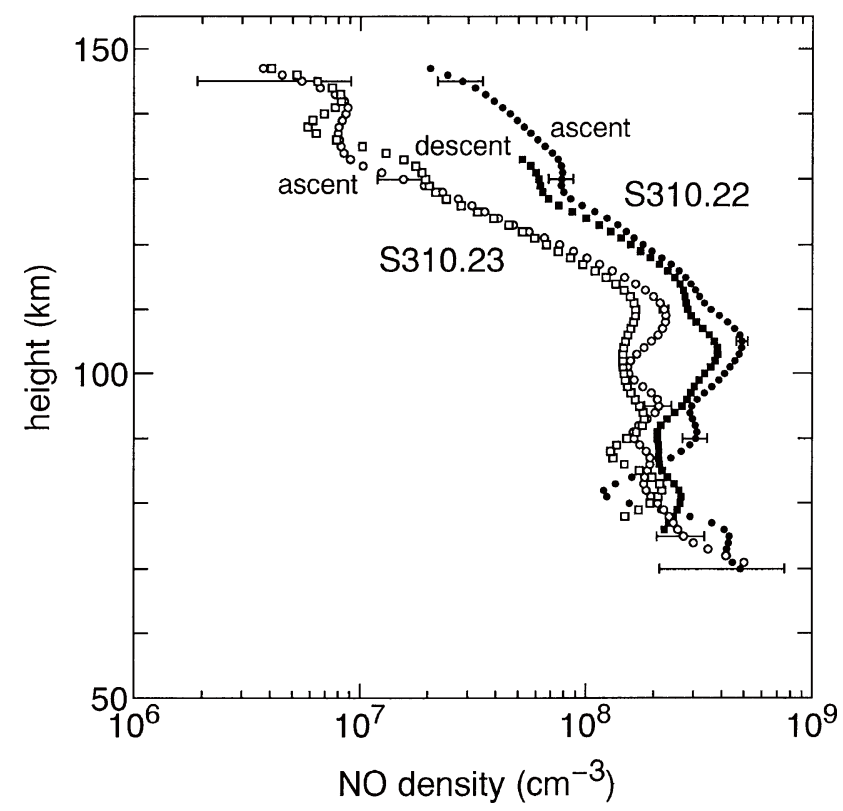

Fig. 3. NO density profiles measured in the S310.22 ascent (dot), S310.22 descent (filled square), S310.23 ascent (open circle) and S310.23 descent (open square). The error bars represent uncertainty due to numerical differentiation of the data with random error. 
nearly constant density plateaus of $2 \times 10^{8} \mathrm{~cm}^{-3}$ between 80 and $110 \mathrm{~km}$. On both of the experiments the NO densities are found to reach $5 \times 10^{8} \mathrm{~cm}^{-3}$ at $70 \mathrm{~km}$. The ascent and descent profiles appear to agree to within a few times the random error although they are separated horizontally by $170 \mathrm{~km}$ each other. The ascent data below $70 \mathrm{~km}$ were omitted because of large random error and of uncertainty in the corrections for self-absorption and for cross-talk from the Rayleigh scattered sunlight. The descent data below $77 \mathrm{~km}$ were lost due to rapid attitude change of the rocket along the re-entry into the thick atmosphere.

Although some auroral particle precipitations were expected during the $S 310.22$ experiment, optical interference due to $\mathrm{N}^{+} 214 \mathrm{~nm}$ doublet emission (e.g. Dalgarno et al., 1981) may be neglected. This is because the present measurement is insensitive to such emissions in nature by utilizing the gas correlation technique (Iwagami, 1981; Iwagami and Ogawa, 1981); the $\mathrm{N}^{+}$doublet emission can pass through the absorption cell filled with NO gas, and is recognized as a part of the background emissions. Such insignificance of the $\mathrm{N}^{+}$ contamination is supported by the fact that the ascent and descent profiles appear to coincide each other within a few times of the random error at most of heights in spite of the separation between the ascent and descent trajectories.

The correction for self-absorption is important in the mesosphere because of larger NO density than at lower latitudes and the long slant ray path of the sunrise geometry. The measured $\chi(1,0)$ band emission rate converted in the zenith direction $4 \pi I$ [photon $\mathrm{cm}^{-2} \mathrm{~s}^{-1}$ ] and NO number density $n_{\mathrm{NO}}\left[\mathrm{cm}^{-3}\right]$ are related each other as

$$
d[4 \pi I(z)] / d z=-g(z) n_{\mathrm{NO}}(z) \exp [-\tau(z)]
$$

where $z$ is height, $g$ [photon $\mathrm{s}^{-1}$ ] is specific emission rate factor of the $\chi(1,0)$ band including the self-absorption effect and $\tau$ is optical thickness at $215 \mathrm{~nm}$ due to $\mathrm{O}_{2}$ and $\mathrm{O}_{3}$ absorption along the slant ray path. $g(z)$ can be calculated from the molecular parameters of $\mathrm{NO}$ and the solar flux, and $\tau(z)$ from the absorption cross sections of $\mathrm{O}_{2}$ and $\mathrm{O}_{3}$ and a model atmosphere. The value of $g$ outside the atmosphere used is $7.88 \times 10^{-6}$ photon $\mathrm{s}^{-1}$, and $250 \mathrm{~K}$ was assumed to calculate the self absorption effect in the same way as Iwagami (1981). The specific emission rate factor is found to decrease to about a half of that outside the atmosphere at $70 \mathrm{~km}$ in both cases (Figs. 4(a) and 4(b)). The uncertainty in the correction for the self-absorption is estimated to be $30 \%$ at $70 \mathrm{~km}$, and that due to cross-talk of the Rayleigh scattered sunlight to be $20 \%$ at $70 \mathrm{~km}$. The NO density data below 70 $\mathrm{km}$ were omitted because the sum of the above mentioned errors and random error exceeds $100 \%$. Uncertainty in the correction in the attenuation of the $215 \mathrm{~nm}$ radiation by $\mathrm{O}_{2}$ and $\mathrm{O}_{3}$ absorption, and the effect of collision deactivation of the $\chi(1,0)$ band fluorescence are much less important than those for the self-absorption and the Rayleigh scattering cross-talk.

In Fig. 5 the NO density profiles measured during the ascents of both experiments are compared with a 2D (twodimensional) model calculation at a middle latitude (Brasseur, 1984) and a measurement at $31^{\circ} \mathrm{N}$ (Iwagami and Ogawa, 1987) under similar solar activities; also in the figure results

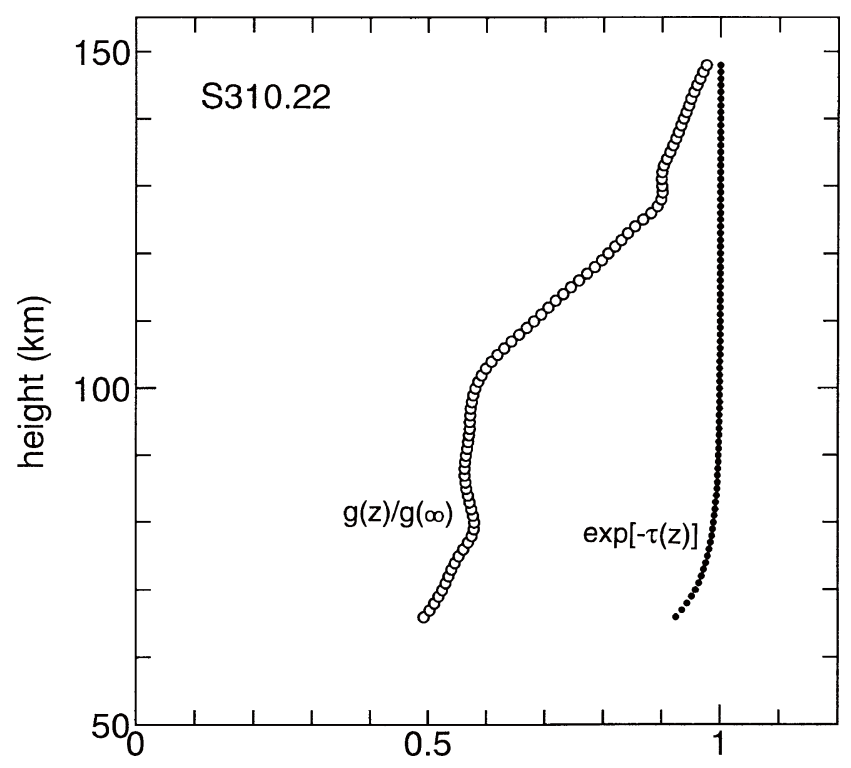

Fig. 4(a). Normalized emission rate factor $g(z) / g(\infty)$ (open circle) and the transmission factor $\exp [-\tau(z)]$ (dot) for the $\mathrm{S} 310.22$ experiment during ascent.

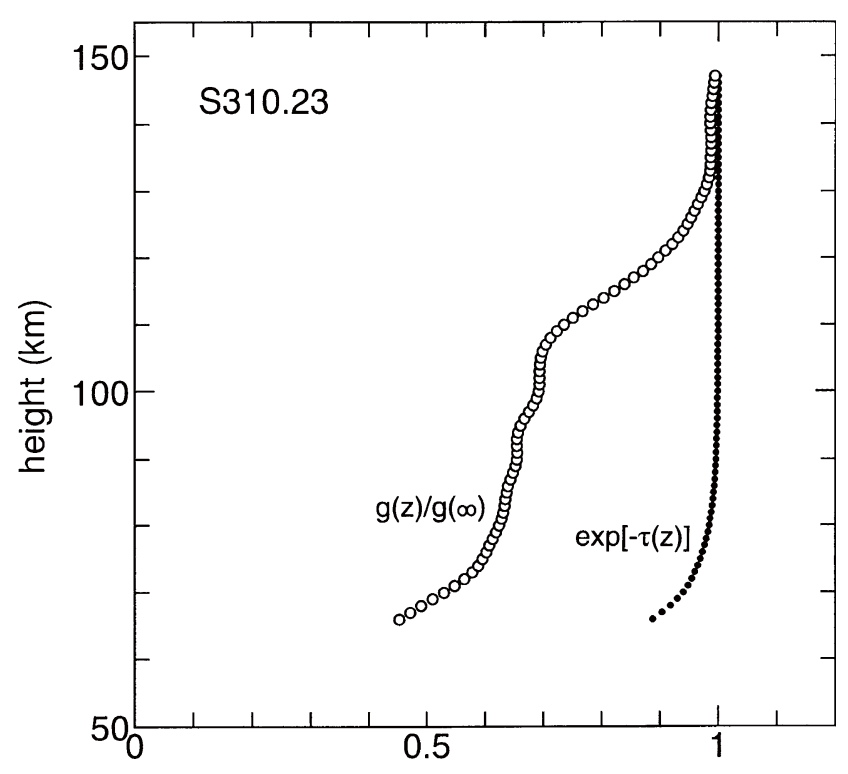

Fig. 4(b). Same as Fig. 4(a) but for the S310.23 experiment.

of simulations by a $1 \mathrm{D}$ (one-dimensional) model at $66^{\circ} \mathrm{N}$ including auroral processes (Siskind, 1994) are shown for comparison. At around $105 \mathrm{~km}$ the NO densities of the present results are larger than those at $31^{\circ} \mathrm{N}$ by a factor of 3 to 10 , and in the $70-90 \mathrm{~km}$ region they are larger than those of the midlatitude model by one to two orders of magnitude. Such enhancement in the NO density in the lower thermosphere may be understood as a consequence of production by auroral particles (e.g. Kondo and Ogawa, 1976; Roble and Rees, 1977) and subsequent downward transport into the mesosphere (e.g. Solomon et al., 1982; Brasseur, 1993). McPeters (1989) investigated the NO column abundance above $1 \mathrm{mb}$ (about $48 \mathrm{~km}$ ) based on the SBUV data of Nimbus 7, and found a maximum column abundance in 


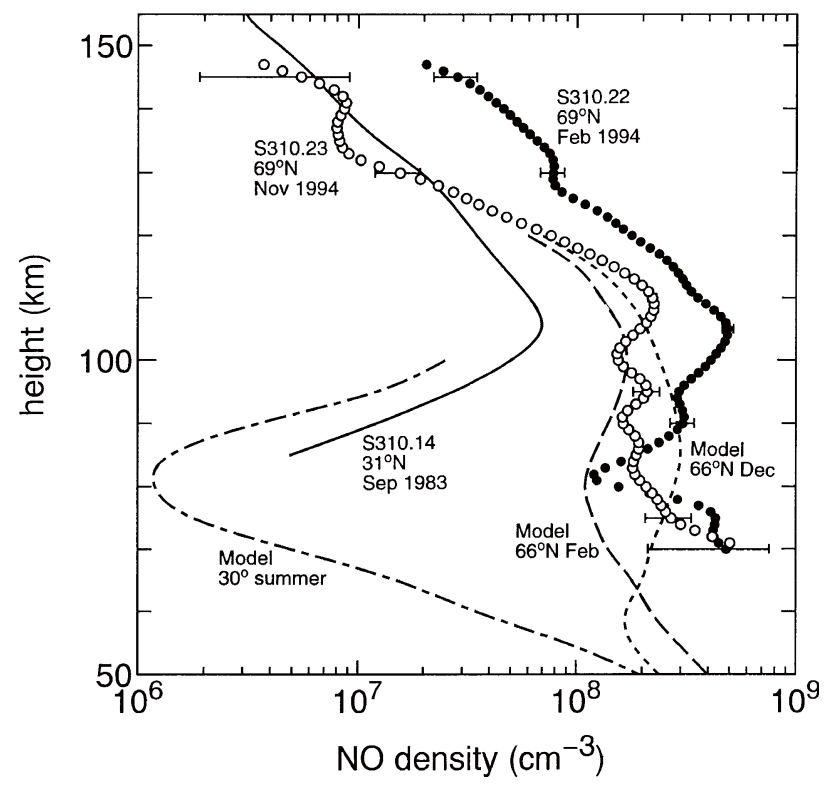

Fig. 5. Comparison of $\mathrm{NO}$ density profiles of the present experiments with a measurement at $31^{\circ} \mathrm{N}$ (solid curve: Iwagami and Ogawa, 1987), and a $2 \mathrm{D}$ model calculation for $30^{\circ}$ summer under low solar activity (dot-dashed curve: Brasseur, 1984). Also compared are model calculations of a $1 \mathrm{D}$ model at $66^{\circ} \mathrm{N}$ including auroral $\mathrm{NO}$ production (Siskind, 1994) for 31 December (dotted curve) and 08 February (dashed curve); they are for the case of high vertical eddy diffusion coefficient $\left(1 \times 10^{6} \mathrm{~cm}^{2} \mathrm{~s}^{-1}\right.$ at $\left.80 \mathrm{~km}\right)$ and without self-shielding effect in the $\delta$ band predissociation.

winter at high latitude of $2 \times 10^{15} \mathrm{~cm}^{-2}$. The $\mathrm{NO}$ column abundances above $50 \mathrm{~km}$ found by the present two experiments are comparable to this value if densities of $5 \times 10^{8}$ $\mathrm{cm}^{-3}$ are assumed between 48 and $70 \mathrm{~km}$. Recently Notholt et al. (1997) reported NO total column abundance of (2.5$3.5) \times 10^{15} \mathrm{~cm}^{-2}$ at Spitsbergen $\left(79^{\circ} \mathrm{N}\right)$ in March.

The larger NO densities found at $100 \mathrm{~km}$ and above in the $\mathrm{S} 310.22$ experiment than in the $\mathrm{S} 310.23$ experiment seem to be due to the higher auroral activity in the several nights prior to the former than that to the latter. The NO abundance in the lower thermosphere reflects the history of auroral activity a few days prior to the experiment (e.g. Kondo and Ogawa, 1976; Roble and Rees, 1977). According to the simulations by Siskind (1994) accumulation of NO needs 10 days to reach a steady state in the lower thermosphere, and more than a month in the lower mesosphere. The steeper density gradient seen in the $\mathrm{S} 310.23$ experiment at $120 \mathrm{~km}$ and above than in the $\mathrm{S} 310.22$ experiment comes from the lower thermospheric temperature due to lower solar activity as noted before.

Before comparing the present results and the model simulations including auroral processes in Fig. 5, it is useful to summarize various time constants relating to the present experiments. The sunlit duration in the mesosphere and above (defined by the duration of solar zenith angles less than $90^{\circ}$ ) was 7 hours in the $S 310.22$ experiment in February while 1 hour in the $\mathrm{S} 310.23$ experiment in November. Since the time constant for the $\delta$ band predissociation is 2 days (Minschwaner and Siskind, 1993) in the thermosphere under full solar illumination (and each predissociation event breaks two NO molecules as a result), the photochemical lifetimes of $\mathrm{NO}$ in the thermosphere are 3.4 days and 24 days, respectively, for the February and November experiments. The photochemical lifetime of $\mathrm{NO}_{x}$ becomes longer at lower heights due to $\mathrm{O}_{2}$ absorption and self-absorption to exceed several months in the stratosphere (Solomon et al., 1982). By assuming vertical eddy diffusion coefficients of $1 \times 10^{6} \mathrm{~cm}^{2} \mathrm{~s}^{-1}$ at $80 \mathrm{~km}$ and of $1 \times 10^{5} \mathrm{~cm}^{2} \mathrm{~s}^{-1}$ at $50 \mathrm{~km}(\mathrm{e} . \mathrm{g}$. Shimazaki, 1985) and a scale height of $6 \mathrm{~km}$, the time constants for the vertical mixing are calculated to be 4 days at $80 \mathrm{~km}$ and 40 days at $50 \mathrm{~km}$, respectively. By assuming vertical wind speed of $1 \mathrm{~cm} \mathrm{~s}^{-1}$ and a scale height of $6 \mathrm{~km}$, the time constant for the vertical advection is calculated to be 7 days. By assuming a latitudinal eddy diffusion coefficient of $3 \times 10^{9} \mathrm{~cm}^{2} \mathrm{~s}^{-1}$ and a scale length of $1000 \mathrm{~km}$, the time constant for the latitudinal mixing is calculated to be 40 days; however, if the diffusion coefficient is much larger due to planetary wave breaking in the $70-110 \mathrm{~km}$ region as inferred by Siskind et al. (1997), the time constant will be a few days. In Fig. 6 latitude-height cross-section of zonal wind in January after CIRA:1986 is shown; those for November, December and February appear to be similar. As seen in the figure the edge of the polar vortex (the latitude of maximum wind speed) is located at $40^{\circ} \mathrm{N}$ in the mesosphere; the enhancement of NO density in the mesosphere is expected to be confined at latitudes higher than $40^{\circ} \mathrm{N}$. In summary the following facts may be expected from the values of the time constants discussed above: The memory of auroral activity may be kept as enhanced NO abundance in the lower thermosphere for a few days both in November and February. In November such enhanced NO may be transported downward to reach the mesosphere after some small photodissociation loss whereas in February after considerable loss. Accumulation of the mesospheric NO abundance in November and a slow decrease in February is expected to occur.

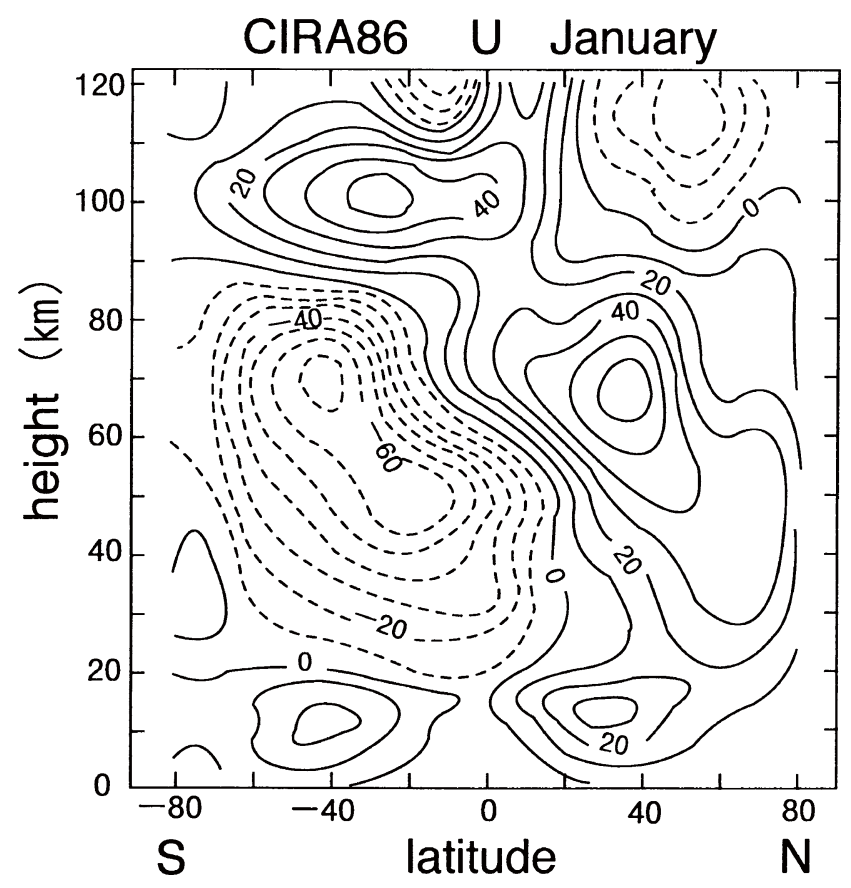

Fig. 6. Latitude-height cross-section of zonal wind speed in January after CIRA:1986. 
In Fig. 5 the NO density profiles obtained by the present measurements are compared again with those of model simulations by Siskind (1994). Those simulations include several situations similar to the actual situations of the present experiments such as the nightly repeating auroral storm although vertical advection and latitudinal mixing are not included in this 1D model. In the model auroral particle precipitation with a characteristic energy of $3 \mathrm{keV}$ and an energy influx of $0.5 \mathrm{erg} \mathrm{cm}^{-2} \mathrm{~s}^{-1}$ occurs for 12 hours every night starting from 01 December through 70 days at a latitude of $66^{\circ} \mathrm{N}$. Such an energy flux gives sub-visual aurora. Although this model simulates cases of high and low vertical eddy diffusion coefficients and with and without NO $\delta$ band self-shielding situations, only the case of high eddy diffusion and without self-shielding is referred to in Fig. 5. The dotted curve represents the NO density distribution on 31 December after 30 days integration; this is suitable to be compared with the results of the $\mathrm{S} 310.23$ experiment in November because $\mathrm{NO}$ accumulation started well before 01 December in case of the actual experiment. As noted in a previous section the energy influx expected prior to the $\mathrm{S} 310.23$ experiment of $0.3 \mathrm{erg} \mathrm{cm}^{-2} \mathrm{~s}^{-1}$ is nearly the same as that assumed in the model. In this case the time constant of photodissociation of 24 days is much longer than that of vertical diffusion of 4 days or downward advection of 7 days, and the auroral NO is transported downward almost without suffering from photodissociation loss. The calculated NO density profile appears to be similar to that of the S310.23 measurement in the $80-110 \mathrm{~km}$ region, and shows a nearly constant value of $3 \times 10^{8} \mathrm{~cm}^{-3}$. The tendency of smaller calculated densities than measured seen at $75 \mathrm{~km}$ and below seems to come from too short integration duration of 30 days in the model; the enhanced NO has not reached lower mesosphere in the model because of slow vertical transport having a time constant of several tens of days.

The dashed curve in Fig. 5 represent the simulated NO density distribution on 08 February after 70 days integration, and is suitable to be compared with the NO density profile of the S310.22 experiment in February. In this case the energy influx is estimated to be $9 \mathrm{erg} \mathrm{cm}^{-2} \mathrm{~s}^{-1}$ which is 20 times larger than that of the model whereas the measured densities are just 3 times larger than the simulated. Although only qualitative agreement is found, it is interesting to note that both of the density profiles by the $\mathrm{S} 310.22$ experiment and that of the simulation appear to show minima at $80 \mathrm{~km}$. This may be due to fast photodissociation in this season; the time constant of photodissociation of 3.4 days in the lower thermosphere is comparable to that of transport of 4 days. The simulation by Siskind (1994) with $\delta$ band self-shielding shows larger densities by a factor of 2-3 in the mesosphere and no minimum at $80 \mathrm{~km}$ (not shown in the figure). Although the self-shielding effect must occur some extent, the present results favor its insignificance. Siskind et al. (1997) also noted that simulations without self-shielding agrees better with HALOE observations than that with selfshielding.

\subsection{Electron and ions}

In Figs. 7(a) and 7(b) electron density profiles measured with the impedance probe are shown. The data in the descents appear to be disturbed by the wake of the rocket; the

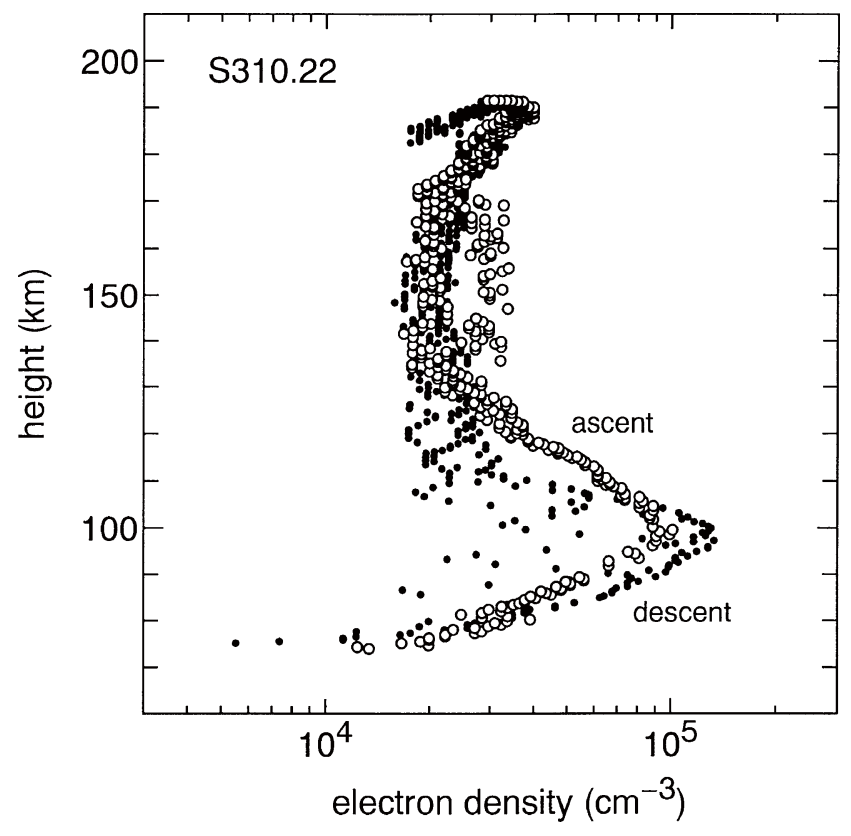

Fig. 7(a). Electron density profiles measured by the impedance probe in the S310.22 experiment during ascent (open circle) and descent (dot).

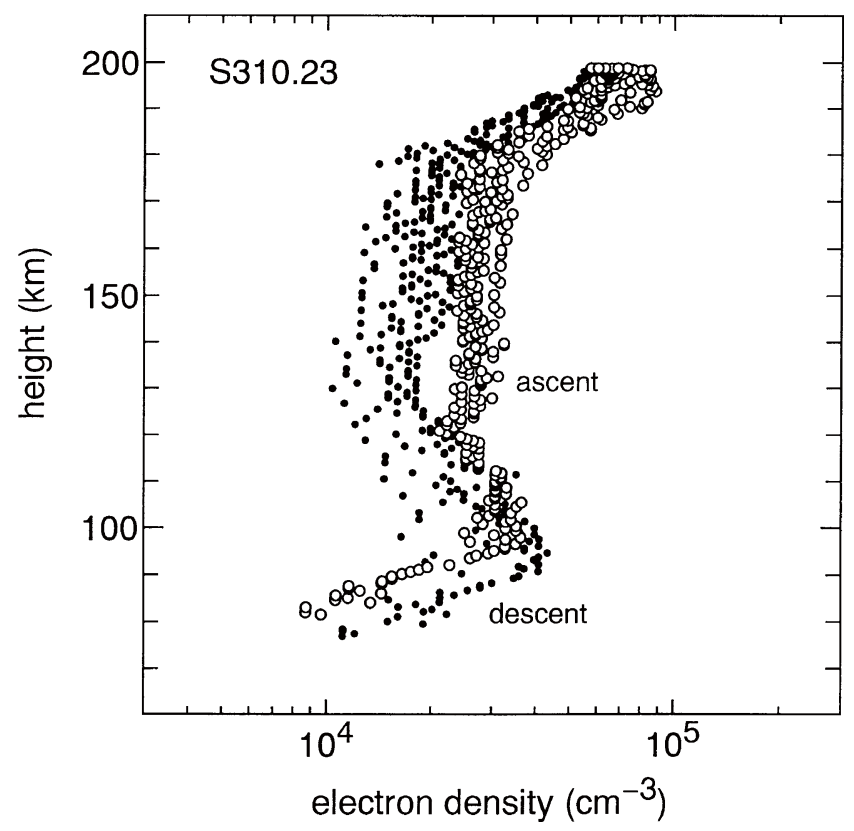

Fig. 7(b). Same as Fig. 7(a) but in the S310.23 experiment.

upper envelopes should be close to the true density distributions. At around $100 \mathrm{~km}$ enhanced electron density peaks of $1 \times 10^{5} \mathrm{~cm}^{-3}$ and $3 \times 10^{4} \mathrm{~cm}^{-3}$ are seen both in the $\mathrm{S} 310.22$ and S310.23 experiments, respectively. According to a model of Kondo and Ogawa (1976) for $70^{\circ}$ latitude equinox without auroral perturbation, the electron density at $100 \mathrm{~km}$ just after the sunrise is only $5 \times 10^{3} \mathrm{~cm}^{-3}$. Those enhancements are partly due to ionization by auroral particle precipitation and also partly due to ionization of enhanced NO by the solar $\operatorname{Ly} \alpha$. According to the above simulation auroral electron precipitation of a characteristic energy of $5 \mathrm{keV}$ and an energy flux of $25 \mathrm{erg} \mathrm{cm}^{-2} \mathrm{~s}^{-1}$ continuing for 30 minutes 
at midnight results in a NO density peak of $3 \times 10^{8} \mathrm{~cm}^{-3}$ at $100 \mathrm{~km}$ just after the precipitation, and causes an electron density peak of $2 \times 10^{4} \mathrm{~cm}^{-3}$ just after sunrise at $100 \mathrm{~km}$.

Under the condition of grazing solar ray incidence just after the sunrise the principal ionization source other than the auroral particle precipitation in the $100 \mathrm{~km}$ region is limited to ionization of $\mathrm{NO}$ by the solar Ly $\alpha$; other solar EUV radiations cannot reach in the $100 \mathrm{~km}$ region due to attenuation along the grazing ray path. Under such conditions the equilibrium between ionization and recombination at 100 $\mathrm{km}$ may be written as

$$
J n_{\mathrm{NO}}+Q=\alpha n_{\mathrm{e}}^{2}
$$

with

$$
J=6 \times 10^{-7} \exp \left[-1 \times 10^{-20} N_{\mathrm{O}_{2}}\right]
$$

where $J\left[\mathrm{~s}^{-1}\right]$ is ionization frequency of $\mathrm{NO}$ by the solar Ly $\alpha$ (Brasseur and Solomon, 1986); $n_{\mathrm{NO}}\left[\mathrm{cm}^{-3}\right]$ is NO density; $Q\left[\mathrm{~cm}^{-3} \mathrm{~s}^{-1}\right]$ is ionization rate due to auroral particle precipitation; $\alpha=2.5 \times 10^{-7} \mathrm{~cm}^{3} \mathrm{~s}^{-1}$ is effective recombination coefficient at $100 \mathrm{~km} ; n_{\mathrm{e}}\left[\mathrm{cm}^{-3}\right]$ is electron density and $N_{\mathrm{O}_{2}}$ [cm-2] is $\mathrm{O}_{2}$ column density along the grazing ray path. $N_{\mathrm{O}_{2}}$ for the S310.22 and S310.23 experiments are evaluated from $\mathrm{O}_{2}$ densities after CIRA:1986 and grazing incidence factors of 24 and 39 , respectively, to be $3 \times 10^{19} \mathrm{~cm}^{-2}$ and 5 $\times 10^{19} \mathrm{~cm}^{-2}$ at $100 \mathrm{~km}$. Substituting NO densities of $5 \times 10^{8}$ $\mathrm{cm}^{-3}$ and $2 \times 10^{8} \mathrm{~cm}^{-3}$ at $100 \mathrm{~km}$ for the $S 310.22$ and $S 310.23$ experiments, respectively, the ionization rate of $\mathrm{NO}$ due to Ly $\alpha$ at $100 \mathrm{~km}$ are found to be $220 \mathrm{~cm}^{-3} \mathrm{~s}^{-1}$ and $73 \mathrm{~cm}^{-3} \mathrm{~s}^{-1}$, respectively. They are $9 \%$ and $32 \%$ of the recombination rate of $2500 \mathrm{~cm}^{-3} \mathrm{~s}^{-1}$ and $225 \mathrm{~cm}^{-3} \mathrm{~s}^{-1}$, respectively, estimated from the measured electron densities of $1 \times 10^{5}$ $\mathrm{cm}^{-3}$ and $3 \times 10^{4} \mathrm{~cm}^{-3}$, respectively; the rest of the ionization must have been provided by the auroral particle precipitation. The electron density enhancements found at $100 \mathrm{~km}$ were mostly due to particle precipitation in the S310.22 experiment, but due to both particle precipitation and Ly $\alpha$ ionization of enhanced NO in the S310.23 experiment. Certain amount of particle precipitations were there even during the S310.23 experiment when the geomagnetic and auroral conditions appeared to be quiet. At $80 \mathrm{~km}$ considerable enhancements in the electron density of $3 \times 10^{4} \mathrm{~cm}^{-3}$ and 1 $\times 10^{4} \mathrm{~cm}^{-3}$ for the $\mathrm{S} 310.22$ and $\mathrm{S} 310.23$ experiments, respectively, are seen again in the same figure. They must be due to ionization by particle precipitation and by auroral $\mathrm{x}$ rays. Ionization of NO by the Ly $\alpha$ did not work at $80 \mathrm{~km}$ because of severe attenuation under the grazing incidence geometry.

The negative to positive ion density ratios measured by the Faraday cup have already been discussed in a separate paper (Amemiya and Nakamura, 1996) for the S310.22 experiment, and those of S310.23 will be discussed in another paper.

\subsection{Ozone}

In Figs. 8(a) and 8(b) the ozone density profiles obtained by the near IR emission and UV absorption techniques are compared with empirical $\mathrm{O}_{3}$ models of CIRA:1986. The

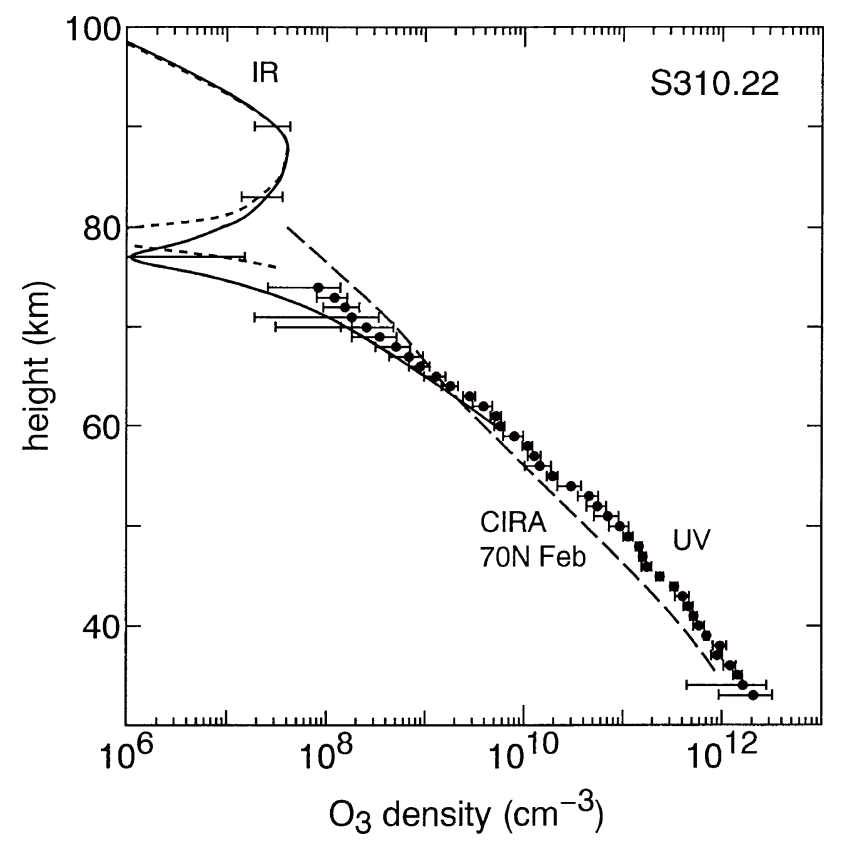

Fig. 8(a). Ozone density distributions obtained by the S310.22 experiment by the near IR emission measurement during ascent (solid curve) and descent (dotted curve) and by the UV absorption measurement during ascent (dot). Those of an empirical model for $70^{\circ} \mathrm{N}$, February of CIRA:1986 (dashed curve) are also plotted for comparison.

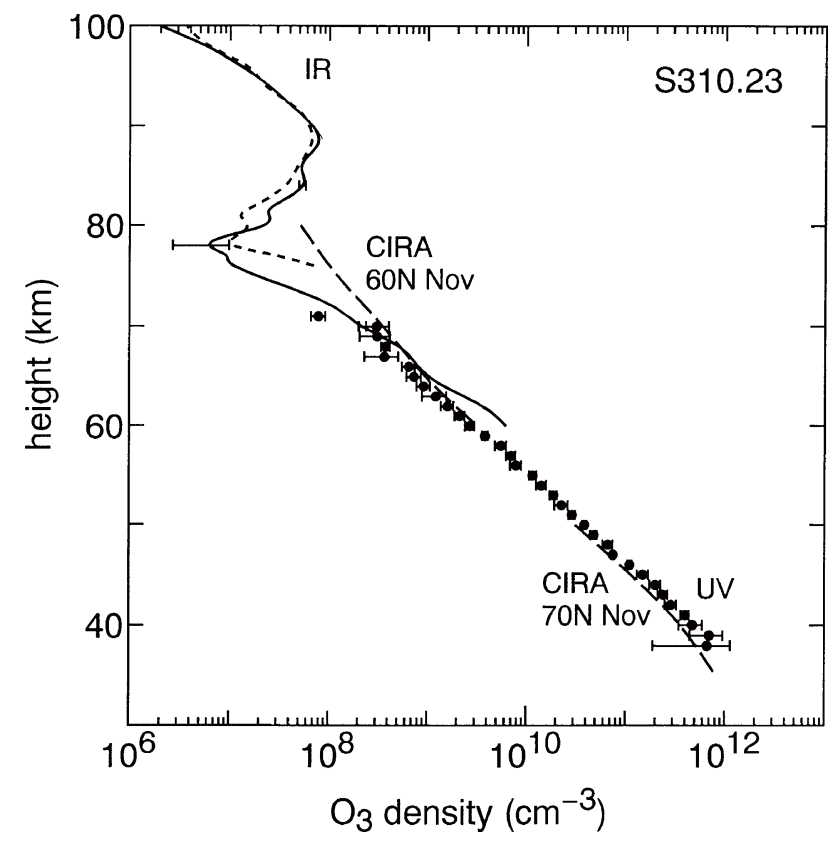

Fig. 8(b). Same as Fig. 8(a) but by the S310.23 experiment. Note that CIRA: $1986 \mathrm{O}_{3}$ model for $60^{\circ} \mathrm{N}$ November is plotted above $60 \mathrm{~km}$ because that for $70^{\circ} \mathrm{N}$ November is available only at $50 \mathrm{~km}$ and below.

error bars represent random error only. The IR emission measurement gives $\mathrm{O}_{3}$ densities at $60 \mathrm{~km}$ and above, and the UV absorption measurement at $70 \mathrm{~km}$ and below. In the height region $60-70 \mathrm{~km}$, results of those two different techniques appear to agree to each other except in the 60-65 $\mathrm{km}$ region of the $\mathrm{S} 310.23$ experiment. This discrepancy may come from the spatial difference in the actual $\mathrm{O}_{3}$ distribution; the IR measurement looked at the zenith direction 
whereas the UV measurement viewed the sun on the horizon. In case of the IR measurements the density profiles below $77 \mathrm{~km}$ during descents are not available because of rapid attitude change of the rocket. The density profiles above $80 \mathrm{~km}$ during ascent and descent by the IR emission measurements mostly agree within the random error. Both of the $\mathrm{O}_{3}$ density profiles obtained by the IR emission radiometer in the $\mathrm{S} 310.22$ and $\mathrm{S} 310.23$ experiments show density maxima of $5 \times 10^{7} \mathrm{~cm}^{-3}$ and $1 \times 10^{8} \mathrm{~cm}^{-3}$, respectively, at around $90 \mathrm{~km}$, and deep minima of $1 \times 10^{6} \mathrm{~cm}^{-3}$ and $5 \times 10^{6} \mathrm{~cm}^{-3}$, respectively, at $78 \mathrm{~km}$. Both of density profiles by the UV absorption radiometers in the S310.22 and S310.23 experiments show monotonous decrease from $6.0 \times 10^{11}$ $\mathrm{cm}^{-3}$ and $4.7 \times 10^{11} \mathrm{~cm}^{-3}$, respectively, at $40 \mathrm{~km}$ to $2.6 \times 10^{8}$ $\mathrm{cm}^{-3}$ and $3.1 \times 10^{8} \mathrm{~cm}^{-3}$, respectively, at $70 \mathrm{~km}$.

The data analysis and error estimations of the IR emission technique have already been described in a separate paper (Yamamoto et al., 1997). The value of Einstein coefficient of the $1.27 \mu \mathrm{m}$ band used is $2.58 \times 10^{-4} \mathrm{~s}^{-1}$ (Badger et al., 1965). Although a new and much smaller value of $1.47 \times$ $10^{-4} \mathrm{~s}^{-1}$ (Hsu et al., 1992) has been reported, a ground based observation favors the old value (Pendleton et al., 1996).

Differences between the present results and the CIRA:1986 model appear to be considerable at $70 \mathrm{~km}$ and above where the measured density profiles show steep gradient to bring about deep minima. Since the CIRA model in this height region is mostly based on the zonal average of the $1.27 \mu \mathrm{m}$ emission measurement on board the SME satellite, there is a possibility that the differences are just a consequence of different vertical and/or horizontal resolution; however, the differences still remain even if the present profiles are degraded to have a vertical resolution of $5 \mathrm{~km}$ (Yamamoto, private communication).

Although the auroral NO is expected to be effective in destroying $\mathrm{O}_{3}$ mostly in spring in the stratosphere according to model simulations (e.g. Solomon et al., 1982; Brasseur, 1993), it is worth checking to see if the $\mathrm{NO}_{x}$ catalytic cycle

$$
\begin{gathered}
\mathrm{NO}+\mathrm{O}_{3} \rightarrow \mathrm{NO}_{2}+\mathrm{O}_{2} \\
\mathrm{NO}_{2}+\mathrm{O} \rightarrow \mathrm{NO}+\mathrm{O}_{2}
\end{gathered}
$$

is playing any role in destroying $\mathrm{O}_{3}$ in the $70-90 \mathrm{~km}$ region under such conditions that NO densities are enhanced from the mid-latitude level by one to two orders of magnitude; $\mathrm{NO}$ densities are even larger than $\mathrm{O}_{3}$ densities in this height region as in the case of air pollution on the surface. The catalytic cycle (4) and (5) needs presence of atomic oxygen to work; atomic oxygen is produced by the Hartley band photodissociation of $\mathrm{O}_{3}$ only in daytime below $80 \mathrm{~km}$ (e.g. Allen et al., 1984). The time constant of $\mathrm{O}_{3}$ destruction by the $\mathrm{NO}_{x}$ cycle in the $70 \mathrm{~km}$ region and below is given as

$$
\tau_{4}=\left(k_{4} n_{\mathrm{NO}} f\right)^{-1},
$$

where $k_{4}$ is the rate coefficient of reaction (4), $f$ is fraction of sunlit duration in the day of the experiment and $n_{\mathrm{NO}}$ is $\mathrm{NO}$ density. Substituting $n_{\mathrm{NO}}=5 \times 10^{8} \mathrm{~cm}^{-3}, k_{4}=3.4 \times 10^{-15}$ $\mathrm{cm}^{3} \mathrm{~s}^{-1}$ at $220 \mathrm{~K}$ (DeMore et al., 1994) and $f=0.29$ ( 7 hours) and $f=0.04$ ( 1 hour), respectively, in the $\mathrm{S} 310.22$ and
S310.23 experiments, $\tau_{4}$ at $70 \mathrm{~km}$ is found to be 23 days and 170 days, respectively. They are much longer than the time constant of dynamical transportation of 4 days. At $90 \mathrm{~km}$ atomic oxygen density is kept at the same level as in daytime even at night. Substituting $n_{\mathrm{NO}}=3 \times 10^{8} \mathrm{~cm}^{-3}, k_{4}=1.3 \times$ $10^{-15} \mathrm{~cm}^{3} \mathrm{~s}^{-1}$ at $190 \mathrm{~K}$ and $f=1, \tau_{4}$ at $90 \mathrm{~km}$ is found to be 30 days. The $\mathrm{NO}_{x}$ cycle is less efficient than the dynamical processes in the 70-90 km region by about one order of magnitude even under such enhanced NO abundance in February, one month after the end of the polar night and one month before the equinox. The steep gradient seen in the measured $\mathrm{O}_{3}$ density distributions in the $70-75 \mathrm{~km}$ region cannot be explained by the chemical loss due to the enhanced $\mathrm{NO}_{x}$ cycle.

At $50 \mathrm{~km}$ where the dynamical time constant also becomes as long as a month, the influence of an enhanced $\mathrm{NO}_{x}$ cycle is expected to appear in the $\mathrm{O}_{3}$ density profiles although the effective sunlit duration decreases due to atmospheric attenuation. According to the limited ability of the measuring technique, NO densities below $70 \mathrm{~km}$ were not obtained in the present experiments. The $\mathrm{O}_{3}$ densities measured by the S310.22 experiment in February are larger than those of the S310.23 experiment in November by factors of 1.3,2.4 and 2.1 at 40,50 and $60 \mathrm{~km}$, respectively, although the sunlit duration was longer in the former than in the latter. This seems to suggest that the $\mathrm{NO}_{x}$ cycle is still less important in destructing $\mathrm{O}_{3}$ in the $40-60 \mathrm{~km}$ region than dynamical processes even in February although NO densities are not available below $70 \mathrm{~km}$. The larger $\mathrm{O}_{3}$ densities in February than in November are also seen in CIRA:1986 model, but the ratios ( 1.1 at $40 \mathrm{~km}$ and 1.4 at $50 \mathrm{~km}$ ) are closer to unity than that of the present measurements (CIRA:1986 model is not available at $60 \mathrm{~km}$ in November). The total number densities of air are also larger in February than in November by $12 \%, 15 \%$ and $13 \%$ at 40, 50 and 60 $\mathrm{km}$, respectively. According to theoretical predictions the most important part of $\mathrm{O}_{3}$ destruction occurs after the spring equinox after the enhanced $\mathrm{NO}$ is transported downward enough into the stratosphere. The present experiment performed one month prior to the spring equinox did not find any evidence of such chemical influence of the auroral NO on the $\mathrm{O}_{3}$ distribution in the stratosphere.

\section{Conclusion}

In the winter polar mesosphere where satellite measurement of NO is absent, NO densities of $(2-5) \times 10^{8} \mathrm{~cm}^{-3}$ were found just before and after the polar night as predicted by several model simulations. In the $70-90 \mathrm{~km}$ region the measured NO densities exceed those of a mid-latitude model by one to two orders of magnitude. The behavior of the enhanced NO density distributions are found to agree semiquantitatively with a 1D model including auroral processes by Siskind (1994). Even under such enhanced NO densities in the 70-90 km region, $\mathrm{O}_{3}$ destruction by the $\mathrm{NO}_{x}$ cycle is found to still be much slower than that of dynamics in the middle of February, one month after the end of the polar night and one month prior to the equinox. The fact that the $\mathrm{O}_{3}$ densities in the 40-60 km region found in February are larger than those found in November again suggests predominance of dynamics over chemistry even in February in 
this height region where the time constant for $\mathrm{O}_{3}$ destruction by the $\mathrm{NO}_{x}$ cycle is expected to become close to that of dynamics. The influence of downward NO transport from the mesosphere on the stratospheric $\mathrm{O}_{3}$ chemistry could not be confirmed. The next experiment should be performed in the most critical instance, the spring equinox period.

Acknowledgments. The authors thank to the people of Andoya Rocket Range and Institute of Space and Astronautical Science for their successful operations. They also thank to Dr. T. Takahashi for providing the rocket attitude data.

\section{References}

Allen, M., J. I. Lunine, and Y. L. Yung, The vertical distribution of ozone in the mesosphere and lower thermosphere, J. Geophys. Res., 89, 48414872, 1984.

Amemiya, H. and Y. Nakamura, Measurement of negative ions in the lower ionosphere (D-layer) in the polar region, J. Geomag. Geoelectr. 48, 391-401, 1996.

Badger, R. M., A. C. Wright, and R. F. Whiltlock, Absolute intensities of the discrete and continuous absorption band of oxygen gas at 1.26 and $1.065 \mu$ and the radiative lifetime of the ${ }^{1} \Delta_{\mathrm{g}}$ state of oxygen, J. Chem. Phys., 43, 4345-4350, 1965.

Brasseur, G., Coupling between the thermosphere and the stratosphere: The role of nitric oxide, Handbook for MAP, 10, 116-121, 1984.

Brasseur, G., The response of the middle atmosphere to long-term and short-term solar variability: A two-dimensional model, J. Geophys. Res., 98, 23079-23090, 1993.

Brasseur, G. and S. Solomon, Aeronomy of the Middle Atmosphere, 2nd ed., 325 pp., D. Reidel Pub. Co., Dordrecht, 1986.

CIRA:1986, COSPAR International Reference Atmosphere, Adv. Space Res., edited by D. Rees, J. J. Burnett, and K. Labitzke, 10(12), pp. 317 and 430, 1990 .

Dalgarno, A., G. A. Victor, and T. W. Hartquist, The auroral 2145 A feature, Geophys. Res. Lett., 8, 603-605, 1981.

DeMore, W. B., S. P. Sander, D. M. Gorden, R. F. Hampson, M. J. Kurylo, C. J. Howard, A. R. Ravishankara, C. E. Kolb, and M. J. Molina, Chemical Kinetics and Photochemical Data for Use in Stratospheric Modeling, JPL Publ. 94-26, 1994.

Foster, J. C., J. M. Holt, R. G. Musgrove, and D. S. Evans, Ionospheric convection associated with discrete levels of particle precipitation, Geophys. Res. Lett., 13, 656-659, 1986.

Horvath, J. J. and J. E. Frederick, In-situ measurements if nitric oxide in the high latitude upper stratosphere, Geophys. Res. Lett., 12, 495-497, 1985.

Hsu, Y. T., Y. P. Lee, and F. Oglivie, Intensities of lines in the band a ${ }^{1} \Delta_{\mathrm{g}}$ $\mathrm{X}^{3} \Sigma_{\mathrm{g}}$ of $\mathrm{O}_{2}$ in absorption, Spectrochem. Acta, 48A, 1227-1230, 1992.

Iwagami, N., Spectroscopic study of the nitrogen airglow, Mem. Natl. Inst. Polar Res., A18, 1-78, 1981.

Iwagami, N. and T. Ogawa, An Antarctic NO density profile deduced from the $\gamma$ band radiometer, Planet. Space Sci., 28, 867-873, 1980.

Iwagami, N. and T. Ogawa, Nitric oxide $\gamma$ band airglow radiometer with a self-absorbing gas cell, Appl. Opt., 20, 2522-2527, 1981.
Iwagami, N. and T. Ogawa, Thermospheric NO profiles observed at the diminishing phase of solar cycle 21, Planet. Space Sci., 35, 191-198, 1987.

Kondo, Y. and T. Ogawa, Odd nitrogen in the lower thermosphere under auroral perturbations, J. Geomag. Geoelectr., 28, 253-282, 1976.

McPeters, R. D., Climatology of nitric oxide in the upper stratosphere, mesosphere, and thermosphere: 1979 through 1986, J. Geophys. Res., 94, 3461-3472, 1989.

Minschwaner, K. and D. E. Siskind, A new calculation of nitric oxide photolysis in the stratosphere, mesosphere and lower thermosphere, $J$. Geophys. Res., 98, 20401-20412, 1993.

Notholt, J., G. C. Toon, R. Lehmann, B. Sen, and J.-F. Blavier, Comparison of Arctic and Antarctic trace gas column abundances from groundbased Fourier transform infrared spectrometry, J. Geophys. Res., 102, 12863-12869, 1997.

Ogawa, T. and T. Watanabe, Rocket-borne optical ozone dropsonde (ROOD) for calibrating the satellite observation of stratospheric ozone, Adv. Space Res., 14(1), 211-214, 1994.

Oya, H. and T. Obayashi, Rocket measurement of ionospheric plasma by gyro-plasma probe, Rep. Ionos. Space Res. Japan, 21, 1-8, 1967.

Pendleton, W. R., D. J. Baker, R. J. Reese, and R. R. O'Neil, Decay of $\mathrm{O}_{2}\left(\mathrm{a}^{1} \Delta_{\mathrm{g}}\right)$ in the evening twilight airglow: Implications for the radiative lifetime, Geophys. Res. Lett., 23, 1013-1016, 1996.

Roble, R. G. and M. H. Rees, Time-dependent study of the aurora: Effects of particle precipitation on the dynamic morphology of ionospheric and atmospheric properties, Planet. Space Sci., 25, 991-1010, 1977.

Rusch, D. W. and C. A. Barth, Satellite measurement of nitric oxide in the polar region, J. Geophys. Res., 80, 3719-3721, 1975.

Rusch, D. W. and R. T. Clancy, A study of the time and spatial dependence of ozone near $1.0 \mathrm{mb}$ with emphasis on the springtime, in Ozone in the Atmosphere, edited by R. D. Bojkov and P. Fabian, 218 pp., Deepak Pub., 1989.

Russell, J. M., S. Solomon, L. L. Gordley, E. E. Remsberg, and L. B. Callis, The variability of stratospheric and mesospheric $\mathrm{NO}_{2}$ in the polar winter night observed by LIMS, J. Geophys. Res., 89, 7267-7275, 1984.

Shimazaki, T., Minor Constituents in the Middle Atmosphere, 141 pp., Terra Scientific Pub., Tokyo, and D. Reidel Pub., Dordrecht, 1985.

Siskind, D. E., On the radiative coupling between mesospheric and thermospheric nitric oxide, J. Geophys. Res., 99, 22757-22766, 1994.

Siskind, D. E. and J. M. Russell, III, Coupling between middle and upper atmospheric NO: Constraints from HALOE observations, Geophys. Res. Lett., 23, 137-140, 1996.

Siskind, D. E., J. T. Bacmeister, M. E. Summers, and J. M. Russell, III, Two-dimensional model calculations of nitric oxide transport in the middle atmosphere and comparison with HALOE data, J. Geophys. Res., 102, 3527-3545, 1997

Solomon, S. and R. R. Garcia, Transport of thermospheric NO to the upper stratosphere?, Planet. Space Sci., 32, 399-409, 1984.

Solomon, S., P. J. Crutzen, and R. G. Roble, Photochemical coupling between the thermosphere and the lower atmosphere 1. Odd nitrogen from 50 to $120 \mathrm{~km}$, J. Geophys. Res., 87, 7206-7220, 1982.

Yamamoto, H., K. Yajima, H. Sekiguchi, and T. Makino, Mesospheric ozone density profiles in the polar region, J. Geomag. Geoelectr., 49, 675-688, 1997. 